\title{
DATOS PARA LA ADAPTACIÓN CASTELLANA DE LA ESCALA DE TEMORES (FSS)
}

\author{
Luls Matesanz
}

\section{RESUMEN}

La escala de temores FSS (Fear Survey Schedule) con 123 items se administró a cuatro muestras independientes, dos de sujetos clínicos (3744 hombres y 424 mujeres) y dos de sujetos no clínicos (290 hombres y 341 mujeres). El análisis de ítems y el análisis factorial dieron como resultado la solución de seis factores con ocho items cada uno como la solución ideal tanto para hombres como para mujeres. Se obtuvieron estructuras factoriales muy semejantes en ambos sexos, con un solo factor diferente, Claustrofobia en hombres y Sensibilidad ante la Violencia en mujeres. Los cinco factores comunes a ambos sexos son: 1. Evaluación social, 2. Temor a animales pequeños, 3. Aprensión ante el sufrimiento, 4. Tendencia obsesiva, y 5. Interacción social. La conclusión principal de nuestro estudio sugiere el análisis de temores por separado para hombres y mujeres como la estrategia más adecuada desde un punto de vista tanto metodológico y como clínico.

Palabras clave: TEMORES; FSS; ADAPTACIÓN DE ESCALAS; ANÁLISIS DE ITEMS; ANÁLISIS FACTORIAL; DIFERENCIAS DE SEXO. 


\section{SUMMARY}

A Spanish version of the Fear Survey Schedule (FSS) with 123 items was administered to four independent samples, two clinic (3.750 men and 420 women) and two non-clinic (290 men and 341 women) samples. Factor analyses indicated the six factor solution with eight items each as the most appropriate for males as well as for females. The factor structures for both sexes were very similar; only a factor was different, Claustrophobia in men, Sensibility to Violence in women. The five factors similar in both sexes were named: 1 . Social Evaluation, 2. Small animal fear, 3. Apprehension about Suffering, 4. Obsessive Tendency, 5. and Social Interaction. It was concluded that that the analysis of fear, performed separately for males and females, is the most adequate strategy from a methodological as well as clinical point of view.

Key words: FEARS; FSS; SCALES ADAPTATION; ITEM ANALYSIS; FAC. TOR ANALYSIS; SEX DIFFERENCES.

\section{INTRODUCCIÓN}

Uno de los principales síntomas de las personas que acuden a la consulta psicológica suele ser el elevado nivel de ansiedad, independientemente del trastorno por el que acuden al terapeuta. Por ello, los psicólogos han desarrollado diversos métodos para evaluar la ansiedad que suele relacionarse con una alta puntuación en las listas de temores. Los inventarios o escalas de temores tienen aplicación tanto en la práctica clínica como en la investigación psicológica.

En la práctica terapéutica las escalas de temores tienen como objetivo determinar no sólo el nivel de ansiedad del paciente que acude a la consulta, sino también la dirección en que se manifiesta dicha ansiedad, según las reacciones fóbicas específicas que presenta cada paciente. Estos instrumentos se aplican asimismo para 
comprobar los cambios que va experimentando el paciente en las diversas fases del tratamiento $y$, en consecuencia, comprobar la eficacia de éste o de diversos modelos de intervención aplicados.

El Inventario de Temores, conocido como el FSS (Fear Survey Schedule), es el más utilizado, desde que Lang y Lazovik (1963) construyeron la primera versión, partiendo del estudio de Akutagawa (1956) y la aplicaron en su experimento para desensibilizar una fobia. Desde entonces los autores han utilizado versiones con diferente número de items en estudios experimentales, en terapia comportamental, en la selección de sujetos para participar en experimentos, en la evaluación de cambios antes y después de la intervención terapéutica, etc. Parece que fue Lang (1963) el primero que la utilizó el FSS de 122 items. Wolpe y Lang (1964) adaptaron el FSS para su aplicación en evaluación clínica. Este inventario consta de 72 items e incluye estímulos de ansiedad neurótica más frecuentes encontrados en pacientes que acuden a consulta psicológica. Geer (1965) empleando una muestra de estudiantes (161 hombres, y 109 mujeres) construyó el FSS de 51 items que se contestan en una escala de 1 (Nada) a 7 (terror), y fue recomendada con fines de investigación.

En cuanto a la metodología del FSS, los autores han empleado diversas estrategias. Wolpe y Lang (1964), partiendo de criterios conceptuales, siguiendo, por lo tanto, una estrategia racional de construcción (Matesanz, 1997) clasificaron los items de este inventario sin datos empíricos y sin la ayuda de técnica psicométrica alguna en seis categorías: ruidos, animales, enfermedades y muerte, fobias clásicas, estímulos sociales o interpersonales, y miscelaneas. Posteriormente otros autores han aplicado el análisis factorial con objeto de analizar el FSS y descubrir las posibles dimensiones de este instrumento, siguiendo, por lo tanto, una metodología más conforme con parámetros psicométricos.

Arrindell y cols. (1991) han analizado treinta y ocho estudios de análisis factorial con el FSS anteriores al año 1991. La mayor parte de los factores identificados en estos estudios pueden clasificarse en una de las cuatro

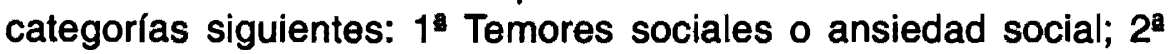
Temores relacionados con lesiones o enfermedades corporales; $3^{\mathrm{a}}$ Temores a animales inofensivos, y $4^{\mathrm{a}}$ Temores agorafóbicos. Los estudios posteriores a 1991 arrojan resultados semejantes. 
No obstante, de los estudios factoriales realizados con el FSS se pueden sacar pocas conclusiones definitivas, dado que los diferentes autores suelen utilizar versiones diferentes del inventario -con 51,72, 77, 88, 100 ó 122 items-, diferentes muestras de sujetos, diferente método de factorización, de rotación, etc. Merece especial consideración el hecho de que algunos de estos análisis factoriales con el FSS han sido realizados con estudiantes y/o de número reducido. Es sabido que el cálculo del análisis factorial, para que los resultados puedan interpretarse con cierta garantia, debe realizarse con muestras de sujetos en una proporción de tres a uno con el número de items analizados.

Otra objeción a estos estudios es que suelen aplicar el análisis estadístico a muestras compuestas de hombres y mujeres, no por separado para ambos sexos, esto último teóricamente aconsejable en estos estudios y, como veremos, en algunos casos necesario si se desea obtener factores independientes para ambos sexos, factores no afectados, pues, por la naturaleza de las muestras y poder valorar justamente el valor discriminativo y valor predictivo del instrumento.

Los pocos estudios que analizan los datos de modo independiente para ambos sexos (Bernstein y Allen, 1969; Braun y Reynolds, 1969; Rubin y cols., 1968); Stratton y Moore, 1977) obtienen estructuras factoriales diferentes en las muestras de varones y de mujeres. Según el estudio comparativo de Stratton y Moore (1977) la estructura factorial más consistente y de mejor interpretación resulta cuando se realizan análisis factoriales separados según el sexo; hecho que también nosotros hemos comprobado en el estudio que presentamos aquí.

Fredrikson y cols. (1996) encontraron asimismo, si bien con otro instrumento, diferencias en la manifestación de temores y fobias específicos según el sexo. Además de estas diferencias, las mujeres suelen obtener puntuaciones más altas en todas las situaciones y objetos de temor, como han puesto de manifiesto numerosos estudios empleando metodologías diferentes.

Si nos limitamos a los análisis factoriales calculados con la versión de 122 items del FSS, los estudios de Rubin y cols. (1969) y Lawlis (1971) son los más conocidos. Rubin y cols. (1969) analizan factorialmente esta versión en una muestra de 238 estudiantes de psicología, 131 hombres, 107 mujeres. De este estudio, aplicando la 
rotación de los factores en una estructura oblicua, surgen cinco factores que representan el $91 \%$ de la varianza total. Los factores obtenidos son los siguientes: (I) temor a animales pequeños; (II) temor a las manifestaciones de hostilidad; (III) temor relacionado con una moralidad y temores sexuales; (IV) temor al aislamiento y a la soledad, y (V) temor al dolor físico.

Lawlis (1971), utilizando también la versión de 122 items, analiza factorialmente los datos recogidos en una muestra de 185 pacientes: 71 con trastornos psicóticos, 47 con trastornos psiconeuróticos y 59 con trastornos de comportamiento. De la muestra, 76 eran hombres y 109 mujeres. El método utilizado en el análisis factorial fue la solución de componentes principales; los factores, que explicaban el 90 por ciento de la varianza total, se les sometió a una rotación de estructura simple oblicua utilizando el criterio promax. De este estudio surgen tres factores: (I) temor a la desaprobación social; (II) temor a animales pequeños, y (III) temor a enfermedades.

El autor saca cuatro conclusiones de su estudio: $1^{\text {a }}$ Los diferentes grupos clínicos (psicóticos, neuróticos y con trastornos comportamentales) muestran deferentes niveles de temores. $2^{2}$ Las mujeres están más predispuestas a expresar los temores que los hombres. $3^{a}$ Los temores generales pueden agruparse en una lista abreviada que facilita la exploración de este campo. $4^{\mathrm{a}} \mathrm{La}$ naturaleza de los grupos aporta validez al instrumento como medida de temores.

\section{NUESTRO ESTUDIO}

Con objeto de elaborar una versión del FSS con aplicación en la población española tanto en la investigación como en la práctica terapéutica, venimos aplicando este instrumento desde hace años a muestras normales y clínicas, de hombres y mujeres.

La elaboración tanto de cuestionarios unidimensionales de personalidad como de inventarios multidimensionales ha descuidado el análisis por separado en hombres y mujeres, lo que genera dimensiones adulteradas por el factor sexo, constituyendo una notable fuente de error en la interpretación de las puntuaciones recogidas con estas medidas (Matesanz, 1997). La validez de un instrumento, 
caracteristica fundamental del mismo y muy apreciada en psicometria, así como las conclusiones que el psicólogo pueda inferir de los datos obtenidos, se pueden ver negativamente afectadas, cuando no se tiene en cuenta la variable sexo en el análisis. Por esta razón, nuestro estudio hace especial hincapié en el análisis de los datos independiente para ambos sexos.

\section{Instrumento}

A la conocida versión de 122 items añadimos uno más (Tener que tomar decisiones) para reforzar un factor (Interacción o Crítica social) obtenido en estudios anteriores. Veremos que este ítem es uno de los que saturan altamente en dicho factor tanto en hombres como en mujeres. En total analizamos, pues, 123 items (ver Apéndice).

Se pidió a los sujetos que contestaran cada ítem según las siguientes instrucciones:

Las frases siguientes se refieren a objetos y experiencias que pueden causarle temor o desagrado. A la derecha se presentan cinco respuestas (NADA, POCO, BASTANTE, MUCHO, MUCHÍSIMO), según el grado de temor o desagrado que ocasione cada situación. Indique con una "X» la respuestas que $V d$. cree corresponde en su caso en la actualidad. Procure, por favor, contestar todas las frases.

Las respuestas se valoraron según una escala likert de 5 puntos ( nada $=1$, poco $=2$, bastante $=3$, mucho $=4$, y muchísimo $=5$ ).

\section{Sujetos}

Nuestro estudio se basa en datos recogidos en cuatro muestras, dos de sujetos no clínicos (290 varones y 341 mujeres) y otras dos muestras clínicas ( 3.750 varones y 420 mujeres). La muestra que denominamos clínica está formada por hombres y mujeres que acudieron a nuestra consulta sexológica, por lo tanto, todos con un problema sexual y/o de pareja. La Tabla 1 contiene los datos socioculturales de las muestras en las que se basa el presente estudio. 
Tabla1. Datos socloculturales de los sujetos en los que se basa el estudio

Tipo de muestra

No clínica

Clínica

\begin{tabular}{|c|c|c|c|c|}
\hline Sexo & Varones & Mujeres & Varones & Mujeres \\
\hline \multirow[t]{2}{*}{$\mathbf{N}$} & 290 & 341 & 3.744 & 424 \\
\hline & $\%$ & $\%$ & $\%$ & $\%$ \\
\hline $\begin{array}{c}\text { Edad } 15-20 \\
21-30 \\
31-40 \\
41-50 \\
51-60 \\
60- \\
\text { Edad media } \\
\text { Rango de edad }\end{array}$ & $\begin{array}{l}11,4 \\
36,0 \\
28,7 \\
11,4 \\
8,0 \\
4,5 \\
33,2 \\
18-65 \\
\%\end{array}$ & $\begin{array}{l}12,9 \\
45,2 \\
25,4 \\
10,6 \\
5,0 \\
0,9 \\
27,2 \\
16-62 \\
\quad \%\end{array}$ & $\begin{array}{l}1,9 \\
29,6 \\
29,6 \\
19,3 \\
13,3 \\
6,3 \\
38,8 \\
16-83 \\
\%\end{array}$ & $\begin{array}{l}4,0 \\
51,4 \\
30,9 \\
11,1 \\
2,6 \\
- \\
31,17 \\
17-59 \\
\%\end{array}$ \\
\hline \multicolumn{5}{|l|}{ Estudios: } \\
\hline PRIMARIOS & 15,6 & 14,8 & $\begin{array}{l}9,3 \\
127\end{array}$ & 8,2 \\
\hline $\begin{array}{l}\text { EGB/Bach. Elem. } \\
\text { BUP/ Bach. Super. }\end{array}$ & $\begin{array}{l}24,2 \\
23,4\end{array}$ & $\begin{array}{l}20,8 \\
19,1\end{array}$ & $\begin{array}{l}12,7 \\
11,0\end{array}$ & $\begin{array}{l}6,6 \\
10,4\end{array}$ \\
\hline COU/PREU/FP & 27,9 & 12,9 & 16,6 & 28,9 \\
\hline Universitarios & 22,3 & 28,8 & 48,8 & 45,3 \\
\hline Estudios técnicos & 6,6 & 3,6 & 1,3 & 0,3 \\
\hline Sin estudios & - & - & 0,3 & 0,3 \\
\hline
\end{tabular}

\section{Metodología}

Con objeto de conocer la naturaleza del universo de items iniciales, de su especificidad según el sexo, de obtener un instrumento más reducido y de analizar las posibles categorías o estructura factorial que podrian surgir del conjunto de items, seguimos los siguientes pasos':

$1^{\circ}$ Cálculo de puntuaciones medias de cada ítem en hombres y mujeres por separado, con objeto de realizar una primera selección de items, considerando el Indice de Endosamiento como criterio de selección.

$2^{2}$ Cálculo de la prueba de sedimentación de Cattell, para calcular la varianza asociada a cada factor y determinar el número ideal de factores extraibles.

' El cálculo de todas las operaciones y cálculos estadísticos a los que hacemos referencia en el presente trabajo utilizamos el SPSS). 
$3^{2}$ Cálculo de diversos análisis factoriales independientes (utilizando el método componentes principales) con las cuatro muestras descritas, con objeto de obtener la estructura factorial que mejor se ajusta al conjunto de items. Analizamos sucesivamente las soluciones de 5, 6, 7 y 8 factores con las cuatro muestras ya mencionadas, utilizando el método varimax como criterio de rotación.

$4^{2}$ Cálculo de fiabilidad alfa o consistencia intema, de asimetría y de curtosis de ciertos items, cuando el análisis factorial no aportaba información suficiente para la selección de ocho elementos en cada factor.

$5^{2}$ Cálculo de la consistencia interna (coeficiente alfa) de las puntuaciones en cada factor independiente para cada sexo y muestra clínica o no clínica.

$6^{2}$ Contraste de hipótesis de medias de los 123 items para ambos sexos y muestra clínica o no clínica mediante la prueba t de Student.

\section{Resultados}

1. Del cálculo del Índice de Endosamiento o media de cada ítem en las cuatro muestras eliminamos de análisis posteriores aquellos items que por sus características psicométricas carecen de poder discriminativo (Tabla 2).

En total rechazamos los 25 items (Tabla 3). De estos 25 items, dos (92 y 98) obtienen una puntuación media demasiado elevada; los restantes 23 tienen puntuaciones medias muy bajas.

2. Los 98 items así elegidos fueron sometidos a una nueva selección mediante diversos análisis factoriales con cada una de las cuatro muestras ya descritas. Estos análisis nos dieron los siguientes resultados:

2.1. El gráfico de sedimentación o screen test de Cattell aconseja la extracción de cinco o seis factores.

2.2. De los diversos análisis realizados concluimos que la mejor solución con nuestros datos es la de seis factores tanto para hombres como para mujeres, con ocho items en cada factor. Estos seis factores explican el 47,9 por ciento de la varianza total en los hombres y el 45,8 por ciento en las mujeres.

2.3. Encontramos en general una semejanza notable en las estructuras factoriales de ambos sexos (Tablas 4, 5, 6, 7). 


\section{Tabla 2.- Medlas de los ftems para las cuatro muestras}

\begin{tabular}{|c|c|c|c|c|}
\hline \multirow[b]{2}{*}{ Item } & \multicolumn{2}{|c|}{$\begin{array}{l}\text { Muestras } \\
\text { No clinicas }\end{array}$} & \multicolumn{2}{|c|}{$\begin{array}{l}\text { Muestras } \\
\text { clinicas }\end{array}$} \\
\hline & $\begin{array}{l}\text { Hombres } \\
\mathrm{N}=290\end{array}$ & $\begin{array}{c}\text { mujeres } \\
N=341\end{array}$ & $\begin{array}{l}\text { Hombres } \\
\mathrm{N}=3.744\end{array}$ & $\begin{array}{l}\text { Mujeres } \\
N=\mathbf{4 2 0}\end{array}$ \\
\hline 1. El nuido de la aspiradora & $2,02 * *$ & 1,78 & 1,68 & 1,64 \\
\hline 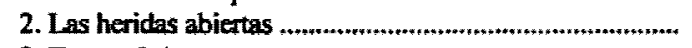 & 2,56 & $2,79 *$ & 2,48 & $2,83^{* *}$ \\
\hline 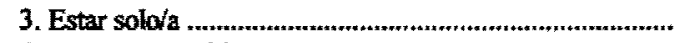 & 1,86 & $2,12 * *$ & 1,80 & $2,15^{* *}$ \\
\hline 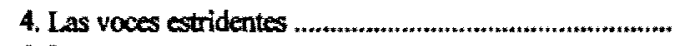 & 2,94 & 2,95 & 2,70 & $286^{* *}$ \\
\hline 5. Las personas muertas & 2,89 & $3,33^{* *}$ & 2,80 & $3,36^{* *}$ \\
\hline 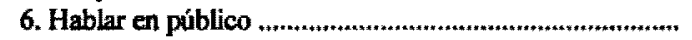 & 2,61 & 2,78 & 2,54 & $289 * *$ \\
\hline 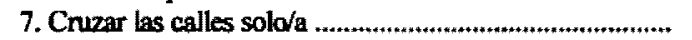 & 1,15 & $1,26^{*}$ & 1,11 & $1,25 * *$ \\
\hline 8. Ver personas que parecen enfermos mentales ,................. & 2,21 & 2,33 & 2,16 & $2,39 * *$ \\
\hline 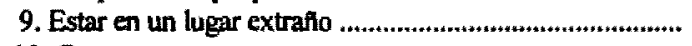 & 1,85 & $2,13 * *$ & 1,81 & $2,09 *$ \\
\hline 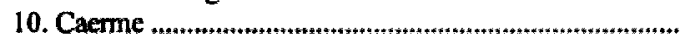 & 2,21 & $2,41^{*}$ & 1,10 & $1,29 * *$ \\
\hline 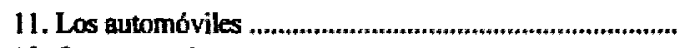 & 1,43 & $1,74^{* *}$ & 1,37 & $179 *$ \\
\hline 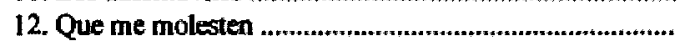 & 2,75 & 2,67 & 2,48 & 2,39 \\
\hline 13. Los dentistas ........, & 2,52 & $2,81^{* *}$ & 2,39 & $2,55^{*}$ \\
\hline 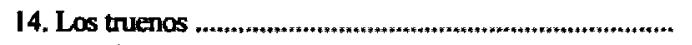 & 1,58 & $2,01 *$ & 1,52 & $1,99^{* *}$ \\
\hline 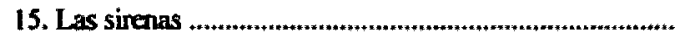 & 1,88 & 2,04 & 1,86 & $2,10^{* *}$ \\
\hline 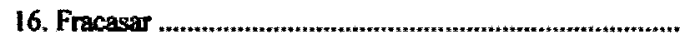 & 3,59 & 3,71 & 3,52 & 3,51 \\
\hline 17. Entrar en una sala donde hay otras personas sentadas .. & 1,81 & 1,75 & 1,72 & 1,76 \\
\hline 18. Los lugares altos en el campo & 1,30 & $1,53^{* *}$ & 1,31 & $1,59 * *$ \\
\hline 19. Mirar hacia abajo desde edificios altos . & 2,17 & $2,41 *$ & 2,34 & $2,51^{*}$ \\
\hline 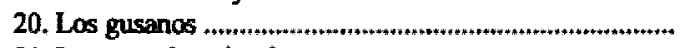 & 1,87 & $2,61 * *$ & 1,79 & $2,56^{* *}$ \\
\hline 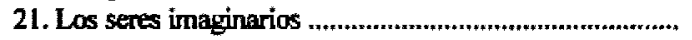 & 1,59 & $1,93 * *$ & 1,49 & $1,87 * *$ \\
\hline 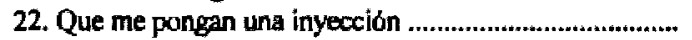 & 2,00 & 2,16 & 1,89 & $2,15^{* *}$ \\
\hline 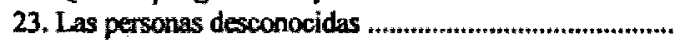 & 1,56 & $1,72^{m *}$ & 1,57 & $1,76^{* *}$ \\
\hline 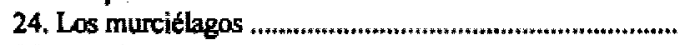 & 1,73 & $2,57^{* *}$ & 1,72 & $2,54 *$ \\
\hline 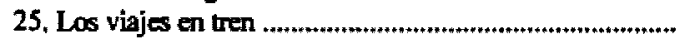 & 1,21 & 1,24 & 1,16 & 1,19 \\
\hline 26. Enfadarme ...., & 2,53 & 2,68 & 2,55 & $2,80^{* *}$ \\
\hline 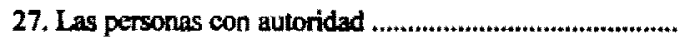 & 2,07 & $2,33 * *$ & 2,16 & $2,49 * *$ \\
\hline 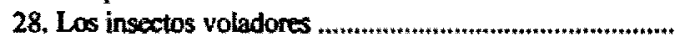 & 1,86 & $2,41 *$ & 1,78 & $2,43 *$ \\
\hline 29, Ver cómo ponen una inyección a otra persona ............... & 1,67 & $1,96 *$ & 1,68 & $2,03 * *$ \\
\hline 30. Los nuidos inesperados & 2,41 & $2,77^{* *}$ & 2,39 & $2,72 *$ \\
\hline 31. Los viajes en coche & 1,32 & $1,57 * *$ & 1,29 & $1,65^{* *}$ \\
\hline 32. El tiempo nebuloso & 1,38 & $1,68 *$ & 1,37 & $1,74^{* *}$ \\
\hline . & 2,29 & 2,37 & 2,17 & $2,36 *$ \\
\hline 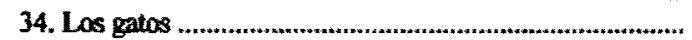 & 1,41 & $1,58^{*}$ & 1,47 & $1,70 *$ \\
\hline 35. Ver cómo una persona atemoriza a otra .......................... & 3,24 & $3,65 * *$ & 3,15 & $3,57 \cdots$ \\
\hline 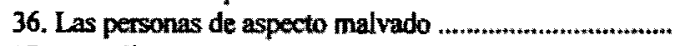 & 2,61 & $3,41^{\text {w* }}$ & 2,65 & $3,30^{* *}$ \\
\hline 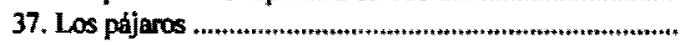 & 1,18 & 1,22 & 1,12 & $1,24 * *$ \\
\hline 38. Ver aguas profundas & 1,89 & $2,26 *$ & 1,81 & $2,19 *$ \\
\hline 39. Que me observen mientras trabajo & 2,02 & $2,55 * *$ & 2,13 & $2,49 * *$ \\
\hline 40. Los animales muertos & 2,22 & $2,96^{* *}$ & 2,21 & 2,93 ** \\
\hline
\end{tabular}


41. Las armas

2,18

42. La suciedad

43. Los viajes en autobús

44. Los insectos que andan a rastras

45. Presenciar una pelea

46. Las personas feas

47. El fuego

48. Las personas enfermas

49. Que me critiquen

50. Las formas extrañas

51. Que otros me toquen

52. Subir en un ascensor

53. Presenciar operaciones quirúrgicas

54. Las personas enfadadas

55. Los ratones o las ratas

56. La sangre humana

57. La sangre de los animales

58. Despedirme de los amigos

59. Los lugares cerrados

60. Pensar que quizá tenga que operame

61. Sentirme rechazado/a por otros

62. Los viajes en avión

63. Los olores a medicina .

64. Sentirme criticado/a por otros .

65. Las serpientes no venenosas

66. Los cementerios

67. Sentirme ignorado/a por los demás

68. La oscuridad

69. No sentir a veces latir el corazón.

70. Los hombres desnudos

71. Las mujeres desnudas

72. Los relámpagos

73. Los médicos

74. Las personas mutiladas o deformes

75. Cometer errores

76. Parecer ridiculo/a

77. Perder el control

78. Desmayarme

79. Sentir náuseas

80. Sentirme diferente a los demás

81. Las arañas inofensivas

82. Tener responsabilidades

83. Ver cuchillos u objetos punzantes

84. Pensar que puedo enfermar mentalmente

85. Hacer exámenes escritos

86. Estar con personas del sexo opuesto
3,06

1,62

2,12

2,90

1,38

2,15

2,16

2,60

1,80

1,97

1,29

2,77

2,41

2.31

2,04

1,86

2,52

1,79

3,06

2,90

1,79

2,01

2,60

2,45

2,27

2,56

1,75

1,90

1,55

1,25

1,55

1,62

2,14

3,05

2,88

3,03

2,58

2,44

1,92

1,85

1,77

1,55

2,88

2,08

1,32
3,20 **

3,52 **

1,65

2,98**

3,56 **

1,40

2,66 **

2,30

$2,94^{* *}$

1,94

$2,41^{* *}$

$1,59 *$

$3,23 *$

2,75 **

3,28 **

$2,39 * *$

2,31 **

2,96 **

2,30 **

3,35 **

$3,29 *$

1,87

2,03

2,96 **

3,24 **

$2,92 * *$

$2,99 * *$

2,18 **

2,17 **

1,41

1,31

$1,98 * *$

1,77

2,33 *

3,16

3,16 *

3,15

2,64

$2,66^{*}$

2,19 *

2,70 **

1,93

1,73 *

$3,32 *$

2,16

1,27
2,06

3,46 **

$1,60 \quad 1,67$

$2,04 \quad 2,93 * *$

$2,90 \quad 3,55^{* *}$

$1,49 \quad 1,44$

$1,91 \quad 2,37$ **

$2,23 \quad 2,31$

$2,88 \quad 3,14^{* *}$

$1,66 \quad 1,97^{* *}$

$1,95 \quad 2,29 * *$

$1,31 \quad 1,55 * *$

$2,95 \quad 3,31$ **

$2,55 \quad 2,91$ **

$2,52 \quad 3,29 * *$

$2,25 \quad 2,57^{* *}$

$1,97 \quad 2,42 * *$

$2,27 \quad 2,73 * *$

$1,91 \quad 2,28$ **

$2,85 \quad 3,01^{*}$

$3,16 \quad 3,45^{* *}$

$1,78 \quad 1,99 * *$

$1,96 \quad 1,99$

$2,89 \quad 3,17^{* *}$

$2,59 \quad 3,23 * *$

$2,33 \quad 2,97 * *$

$2,74 \quad 3,15$ **

$1,83 \quad 2,41 *$

1,82 1,98*

$1,65 * 1,51$

$1,21 \quad 1,38$ **

$1,53 \quad 2,03 * *$

$1,55 \quad 1,76$ *

$2,22 \quad 2,45 *$

$3,12 \quad 3,32 *$

$3,19 \quad 3,36$ **

$3,17 \quad 3,36$ **

$2,47 \quad 2,43$

$2,41 \quad 2,47$

$2,07 \quad 2,31$ **

$1,85 \quad 2,55$

$1,88 \quad 2,05^{* *}$

$1,54 \quad 1,93 *$

$2,82 \quad 3,24^{* *}$

$2,02 \quad 2,18 * *$

$1,37 \quad 1,35$ 
87. Los espacios grandes y abiertos

1,09

1,35

2,17

2,17

3,68

3,57

1,99

1,40

2,31

$2,86 *$

3,19

4,23

2,38

$1,57 *$

3,32

2,59

1,22

1,47

2,09

1,64

3,48

3,32

1,79

1,65

1,54

1,31

2,90

1,71

1,40

1,19

1,55

2,97

3,68

1,69

1,62

1,74

1,73
1,11

2,38 *

$2,82 *$

3,84

4,01**

2,35 **

1,45

$2,57 *$

2,33

3,23

$4,54 * *$

2,90 **

1,39

$3,77 * *$

2,99**

1,17

1,54

2,07

$2,24 * *$

3,72 *

3,27

1,92

2,09 *

1,50

1,27

3,97 *

2,21 **

$1,70^{* *}$

1,18

2,00 **

3,14

$4,11^{* *}$

$2,25 * *$

1,70

1,69

2,05 **
$1,09 \quad 1,13$

$1,38 \quad 1,57^{* *}$

$2,07 \quad 2,17$

$2,10 \quad 2,49 * *$

$3,19 \quad 3,39 * *$

$3,48 \quad 3,77 *$

$2,15 \quad 2,49 * *$

$1,49 \quad 1,49$

$2,20 \quad 2,20$

$2,61 * 2,08$

$3,17 \quad 3,18$

$4,15 \quad 4,43^{* *}$

$2,63 \quad 2,88^{* *}$

$1,41 \quad 1,39$

$3,46 \quad 3,69^{* *}$

$2,36 \quad 2,65 * *$

$1,21 \quad 1,27$

$1,31 \quad 1,34$

$2,05 \quad 2,23 * *$

$1,72 \quad 2,22 *$

$3,35 \quad 3,32$

$3,97 * * 3,78$

$1,63 \quad 1,63$

$1,65 \quad 2,31^{* *}$

$1,51 \quad 1,58$

$1,19 \quad 1,25$

$2,56 \quad 3,55 * *$

$1,71 \quad 2,17 * *$

$1,43 \quad 1,72 * *$

$1,14 \quad 1,20$

$1,57 \quad 1,97 * *$

$2,68 \quad 2,78$

$3,61 \quad 3,81^{* *}$

$1,62 \quad 2,04 * *$

$1,59 \quad 1,72^{*}$

$1,59 \quad 1,55$

$1,892,32 * *$

$\star p<0.05 ; \star * p<0.01$ 


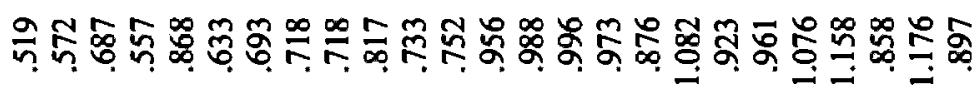

急焉

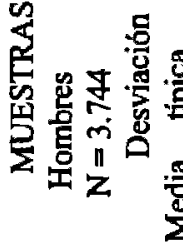

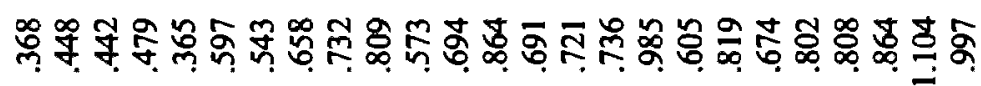

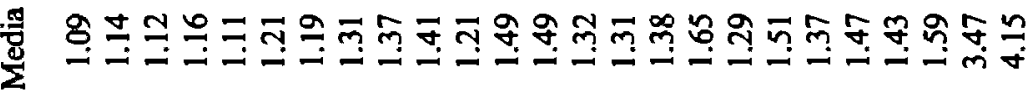

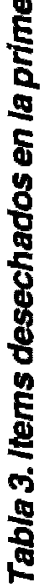

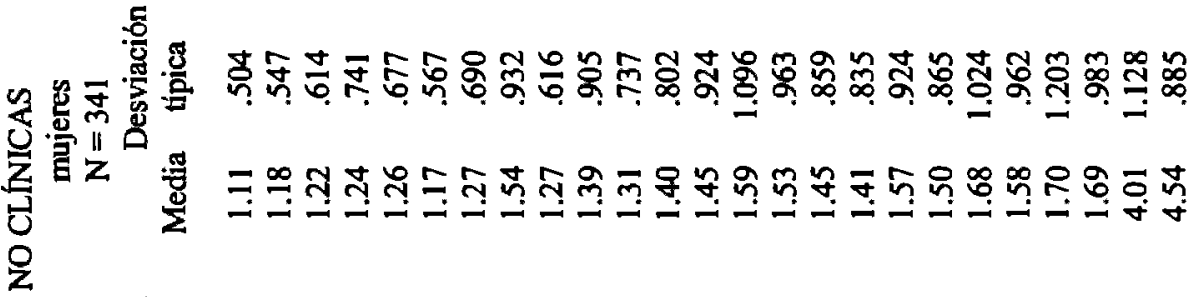

42

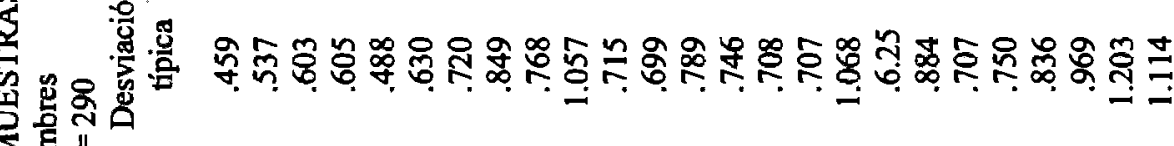
$\sum$

承 江
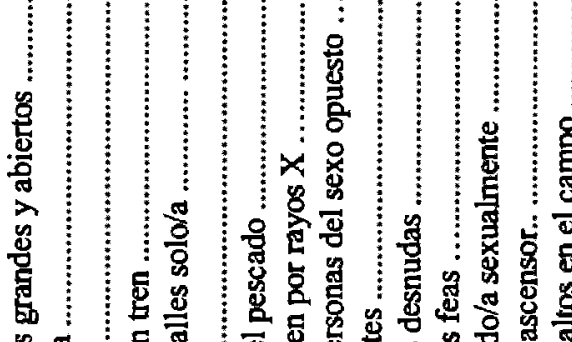

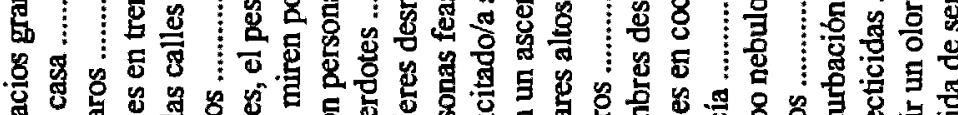

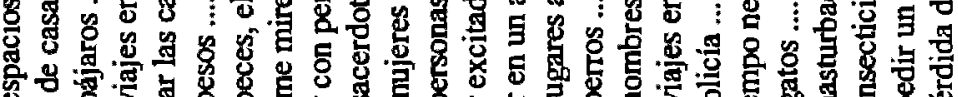

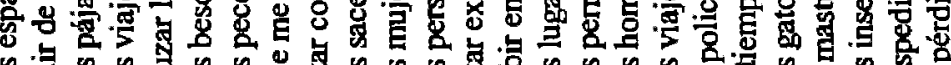

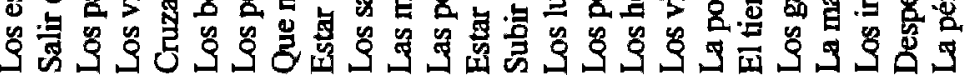
严 
Tabla 4. Matrlz de la estructura factorial después de la rotación.

Saturaciones de cada varlable en los sels factores

Muestra clínica de hombres $(\mathrm{N}=3744)$. Método de factorización: Análisis de Componentes principales. Valores perdido reemplazados por la media.

Rotación varimax, convergente en 7 iteraciones.

Factor 1 Factor 2 Factor 3 Factor 4 Factor 5 Factor 6

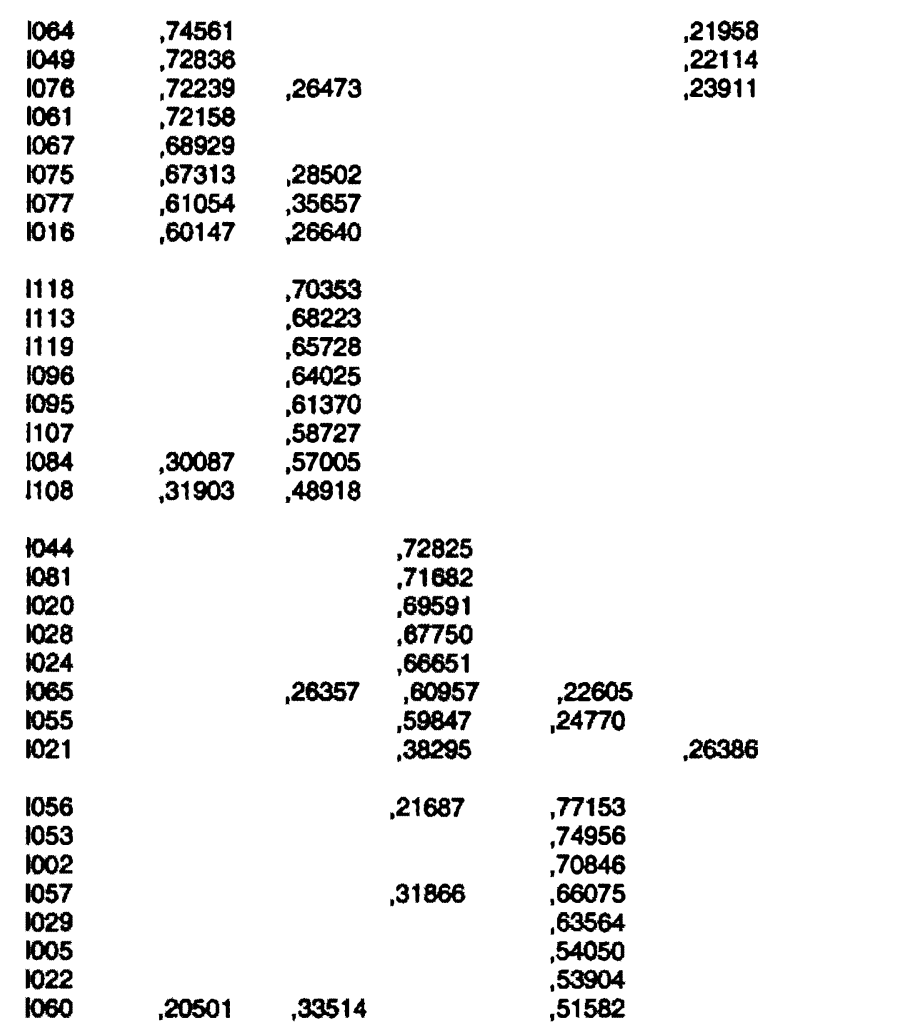




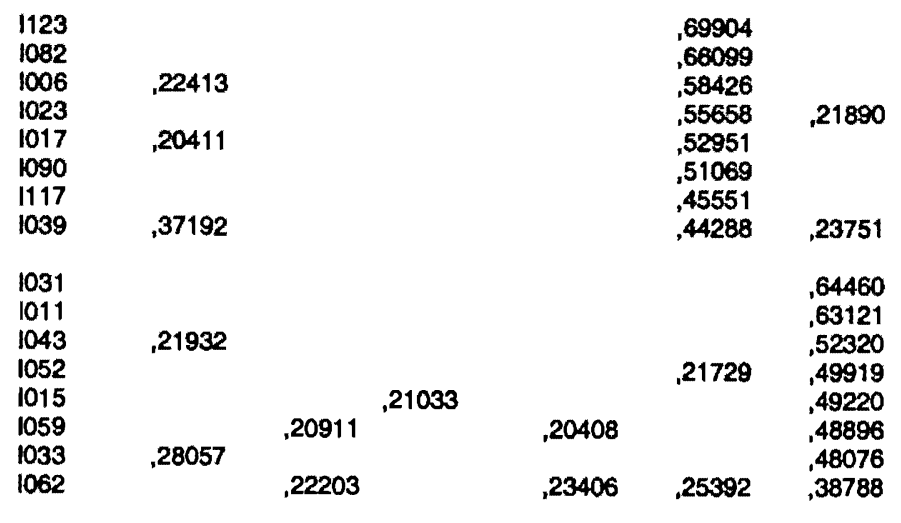

NOTA: En la matriz se han eliminado los ceros delante de las comas y las saturaciones inferiores a 0,20 , con objeto de facilitar la composición de los factores.

Tabla 5. Matriz de la estructura factoriai después de la rotación. Saturaciones de cada variable en los sels factores

Muestra clínica de mujeres $(N=424)$. Método de factorización: Análisis de Componentes principales. Valores perdido reemplazados por la media.

Rotación varimax, convergente en 7 iteraciones.

$\begin{array}{llllll}\text { Factor } 1 & \text { Factor } 2 & \text { Factor } 3 & \text { Factor } 4 & \text { Factor } 5 & \text { Factor } 6\end{array}$

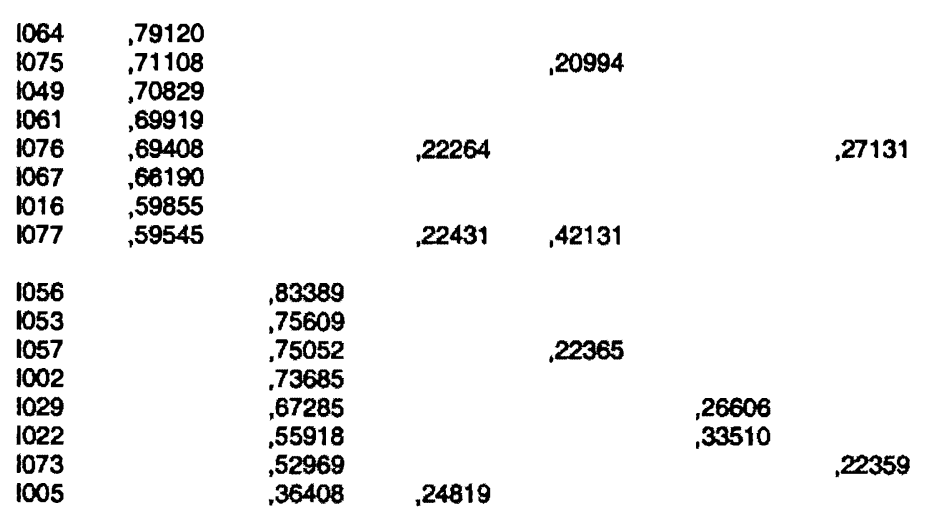




\begin{tabular}{|c|c|c|c|c|c|c|}
\hline $\begin{array}{l}1119 \\
1118 \\
1113 \\
1107 \\
1095 \\
1084 \\
1108 \\
1102\end{array}$ & $\begin{array}{l}.25945 \\
.24122\end{array}$ & & $\begin{array}{l}, 63936 \\
, 60924 \\
, 60630 \\
, 56987 \\
, 56355 \\
, 55549 \\
, 54706 \\
, 52228\end{array}$ & $\begin{array}{l}21375 \\
, 21173\end{array}$ & & \\
\hline $\begin{array}{l}1035 \\
1045 \\
1036 \\
1054 \\
1026 \\
1004 \\
1041 \\
1033\end{array}$ & $\begin{array}{l}30492 \\
.29323\end{array}$ & & $\begin{array}{l}26867 \\
.22556\end{array}$ & $\begin{array}{l}.75721 \\
.62600 \\
.61647 \\
.59153 \\
.56736 \\
.53675 \\
.51433 \\
.45303\end{array}$ & 21511, & 39854, \\
\hline $\begin{array}{l}1081 \\
1044 \\
1020 \\
1028 \\
1024 \\
1055 \\
1065 \\
1021\end{array}$ & & $\begin{array}{l}28321 \\
.29750\end{array}$ & $\begin{array}{l}28981 \\
.25150\end{array}$ & 22326, & $\begin{array}{l}, 73129 \\
.71071 \\
.69510 \\
.69419 \\
.62628 \\
.54828 \\
, 48139 \\
.28451\end{array}$ & \\
\hline $\begin{array}{l}1023 \\
1017 \\
1082 \\
1006 \\
1123 \\
1009 \\
1039 \\
1090\end{array}$ & $\begin{array}{l}20910 \\
\text { 29039 }\end{array}$ & & $\begin{array}{l}\text {,31726 } \\
\text { 29141 }\end{array}$ & & & $\begin{array}{l}68033 \\
.65187 \\
.62725 \\
.60047 \\
.58132 \\
.52591 \\
.48626 \\
, 37006\end{array}$ \\
\hline
\end{tabular}

NOTA: En la matriz se han eliminado los ceros delante de las comas y las saturaciones inferiores a 0,20 , con objeto de facilitar la composición de los factores. 
Tabla 6. Matriz de la estructura factorial después de la rotación. Saturaclones de cada varlable en los seis factores

Muestra no clínica de hombres $(\mathrm{N}=290)$. Método de factorización: Análisis de Componentes principales. Valores perdido reemplazados por la media. Rotación varimax, convergente en 8 iteraciones.

\begin{tabular}{|c|c|c|c|c|c|c|}
\hline & Factor 1 & Factor 2 & Factor 3 & Factor 4 & Factor 5 & Factor 6 \\
\hline 1061 &, 75180 & & & & 20405 & \\
\hline 1076 &, 73694 & 20180 & & & & \\
\hline 1075 & ,70167 &, 31460 & & & 24664 & \\
\hline 1067 & .69667 & & & & 26071 & \\
\hline 1064 & ,69269 & & & & & \\
\hline 1077 & ,68053 & 21323 & & & & \\
\hline 1049 & .67147 & & & & ,29540 & \\
\hline 1016 & ,59185 & ,27887 & & & & \\
\hline 1118 & & .66252 & & & & \\
\hline 1119 & 22252 & .63633 & & & & \\
\hline 1113 & 22380 &, 62644 & & & & \\
\hline 1084 & 25037 & .60715 & & & & \\
\hline 1108 & .34328 & .59797 & & & & \\
\hline 1096 & & .59685 & & & & \\
\hline $\begin{array}{l}1107 \\
1095\end{array}$ & & $\begin{array}{l}, 53296 \\
, 48275\end{array}$ & & & &, 23109 \\
\hline $\begin{array}{l}1056 \\
1053 \\
1002\end{array}$ & & ,24500 & $\begin{array}{l}.79033 \\
.74954 \\
.63009\end{array}$ & & & \\
\hline $\begin{array}{l}1057 \\
1005\end{array}$ & & 28391 & .61775 & ,24428 & & \\
\hline $\begin{array}{l}1005 \\
1029\end{array}$ & & & $\begin{array}{l}.54616 \\
.52771\end{array}$ & &, 26630 & \\
\hline 1022 & & & .50920 & & 28909 & \\
\hline 1060 & & .47720 & .42813 & & 20392 & \\
\hline 1044 & & & & ,72322 & & \\
\hline 1024 & & & &, 71339 & & \\
\hline 1020 & & & & 64564 & & \\
\hline 1028 & & & & .64345 & & \\
\hline $\begin{array}{l}1055 \\
1081\end{array}$ & & & & $\begin{array}{r}61908 \\
61495\end{array}$ & & \\
\hline 1065 & & ,30851 & ,34649 & .45712 & & ,22799 \\
\hline
\end{tabular}




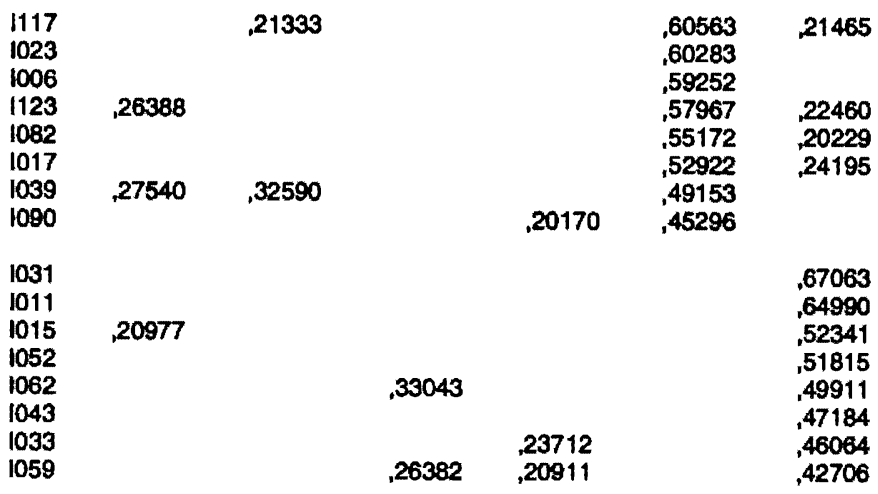

NOTA: En la matriz se han eliminado los ceros delante de las comas y las saturaciones inferiores a 0,20 , con objeto de facilitar la composición de los factores.

Tabla 7. Matriz de la estructura factorlal después de la rotación. Saturaclones de cada variable en los sels factores.

Muestra no clínica de mujeres $(\mathrm{N}=341)$. Método de factorización: Análisis de Componentes principales. Valores perdido reemplazados por la media. Rotación varimax, convergente en 7 iteraciones.

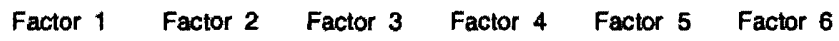

\begin{tabular}{|c|c|c|c|c|c|c|}
\hline $\begin{array}{l}1056 \\
1057 \\
1002 \\
1053 \\
1022 \\
1029 \\
1005 \\
1073\end{array}$ & $\begin{array}{l}.84916 \\
.81995 \\
.71509 \\
.70921 \\
.66052 \\
.65259 \\
.56200 \\
.54830\end{array}$ & & $\begin{array}{l}21791 \\
.20538\end{array}$ & & & 31904 \\
\hline $\begin{array}{l}1064 \\
1049 \\
1061 \\
1076 \\
1067 \\
1075 \\
1016 \\
1077\end{array}$ & 24462 & $\begin{array}{l}.78781 \\
.73822 \\
.72181 \\
, 72140 \\
.69980 \\
.65656 \\
.54580 \\
.50835\end{array}$ & & $\begin{array}{l}21778 \\
.30991 \\
.35378 \\
, 25918\end{array}$ & $\begin{array}{l}.27502 \\
.44634\end{array}$ & 20856, \\
\hline
\end{tabular}




\begin{tabular}{|c|c|c|c|c|c|c|}
\hline $\begin{array}{l}1020 \\
1044 \\
1081 \\
1028 \\
1024 \\
1065 \\
1055 \\
1021 \\
1084 \\
1118 \\
1119 \\
1095 \\
1113 \\
1108 \\
1107 \\
1102\end{array}$ & $\begin{array}{l}\text {,21778 } \\
, 29310 \\
, 33018\end{array}$ & .30150 & $\begin{array}{l}, 76543 \\
, 74779 \\
.70184 \\
.69356 \\
.66089 \\
.64106 \\
.53746 \\
, 39746\end{array}$ & $\begin{array}{l}.22307 \\
.26046 \\
.66530 \\
.65255 \\
.63898 \\
.63144 \\
.62265 \\
.59386 \\
.58979 \\
.53630\end{array}$ & $\begin{array}{l}24214 \\
, 23495\end{array}$ & \\
\hline $\begin{array}{l}1035 \\
1045 \\
1054 \\
1036 \\
1026 \\
1041 \\
1033 \\
1004\end{array}$ & $\begin{array}{l}\text { 20508 } \\
, 21919 \\
, 33939\end{array}$ & $\begin{array}{l}.30492 \\
, 37499 \\
.21487\end{array}$ & $\begin{array}{l}26364 \\
.21353\end{array}$ & $\begin{array}{l}\text {,34520 } \\
\text { 24951 }\end{array}$ & $\begin{array}{l}.73886 \\
.69054 \\
.55708 \\
.54992 \\
.51477 \\
.47835 \\
.37728 \\
., 37513\end{array}$ & . \\
\hline $\begin{array}{l}1023 \\
1082 \\
1017 \\
1006 \\
1123 \\
1009 \\
1090 \\
1039\end{array}$ & 25572, & ,25771 & $\begin{array}{l}26515 \\
.26836\end{array}$ & & & $\begin{array}{r}.69462 \\
.58873 \\
.58848 \\
.51766 \\
.50592 \\
.47808 \\
.47104 \\
.43009\end{array}$ \\
\hline
\end{tabular}

NOTA: En la matriz se han eliminado los ceros delante de las comas y las saturaciones inferiores a 0,20 , con objeto de facilitar la composición de los factores.

2.4. La naturaleza de uno de los factores, el señalado como Factor $V$, es totalmente diferente en ambos sexos; este resultado lo hemos podido confirmar al extraer 5, 6, 7 y 8 factores. Dicho factor lo hemios identificado como CLAUSTROFOBIA en el caso de los hombres, y no aparece en ninguno de nuestros análisis efectuados con mujeres, en las que, no obstante, identificamos un factor (el V) que parece reflejar la SENSIBILIDAD ANTE LA VIOLENCIA (véanse más abajo los items que lo componen). 
2.5. Si bien los resultados avalan la solución de seis factores como la más adecuada tanto para hombres como para mujeres y encontramos en general una semejanza notable en las estructuras factoriales de ambos sexos, debemos anotar, no obstante, las siguientes observaciones:

a) Los factores I y II constan de idénticos items para ambos sexos.

b) El factor III tiene siete items idénticos para ambos sexos; un ítem (Pensar que quizá tenga que operarme) forma parte únicamente de la solución en los hombres; otro ítem (Los médicos) forma parte únicamente de la solución en las mujeres.

c) El factor IV consta de siete items idénticos para ambos sexos; un octavo ítem (Tener pensamientos homosexuales) forma parte únicamente de la solución en los hombres; y otro ítem (Dejar abierta la puerta de la calle) forma parte únicamente de la solución en las mujeres.

d) El factor VI consta de siete items idénticos para ambos sexos; un ítem (Los reconocimientos corporales) forma parte únicamente de la solución en los hombres; otro ítem (Estar en un lugar extraño) forma parte únicamente de la solución en las mujeres.

3. A continuación ofrecemos las seis dimensiones correspondientes a los seis factores extraídos, cuya naturaleza puede deducirse del contenido de los items que los componen:

3.1. Factor I en ambos sexos: EVALUACIÓN SOCIAL NEGATIVA. Temor a la desaprobación social. Está compuesto por los siguientes items:

67. Sentirme ignorado/a por los demás

64. Sentirme criticado/a por otros

61. Sentirme rechazado/a por otros

75. Cometer errores

49. Que me critiquen

76. Parecer ridículo/a

16. Fracasar

77. Perder el control.

3.2. Factor II en ambos sexos: FOBIAA LOS ANIMALES. Items:

20. Los gusanos

44. Los insectos que andan a rastras

81. Las arañas inofensivas 
65. Las serpientes no venenosas

24. Los murciélagos

28. Los insectos voladores

55. Los ratones o las ratas

21. Los seres imaginarios

3.3. Factor III en ambos sexos: APRENSIÓN AL SUFRIMIENTO. Items:

57. La sangre de los animales

56. La sangre humana

22. Que me pongan una inyección

29. Ver como ponen una inyección a otra persona

02. Las heridas abiertas

53. Presenciar operaciones quirúrgicas

05. Las personas muertas

60. Pensar que quizá tenga que operarme (En hombres)

73. Los médicos (En mujeres)

3.4. Factor IV en ambos sexos: TENDENCIA OBSESIVA. Items:

118. Los pensamientos de suicidio

84. Pensar que puedo enfermar mentalmente

113. Pensar que pueden abusar sexualmente de mí

119. Pensar que puedo tener un hijo anormal

95. Que Dios me castigue

107. Dejar el gas abierto

108. La incapacidad sexual (Disfunción eréctil / Anorgasmia)

96. Tener pensamientos homosexuales (En hombres)

102. Dejar abierta la puerta de la calle (En mujeres)

3.5. Factor $V$ en hombres: CLAUSTROFOBIA. Items:

11. Los automóviles

31. Los viajes en coche

59. Los lugares cerrados

52. Subir en un ascensor

62. Los viajes en avión

33. La multitud

43. Los viajes en autobús

15. Las sirenas

Factor V en mujeres: SENSIBILIDAD ANTE LA VIOLENCIA. Items:

35. Ver cómo una persona aterroriza a otra 
45. Presenciar una pelea

54. Las personas enfadadas

36. Las personas de aspecto malvado

26. Enfadarme

41. Las armas

04 . Las voces estridentes

33. La multitud

3.6. Factor VI en ambos sexos: INTERACCIÓN SOCIAL. Items:

123. Tener que tomar decisiones

82. Tener responsabilidades

17. Entrar en una sala donde hay otras personas sentadas

23. Las personas desconocidas

06. Hablar en público

90. Que me vean con rayos $X$

39. Que me observen mientras trabajo

117. Los reconocimientos corporales (En hombres)

9. Estar en un lugar extraño (En mujeres)

4. La fiabilidad de los seis factores (Tabla 8) muestra una consistencia que puede considerarse, teniendo en cuenta el reducido número de ítems en cada factor, como bastante aceptable, sobre todo en los cuatro primeros que prácticamente no son inferiores a 0.80 .

Tabla 8. Flabllidad de los factores en las cuatro muestras

\begin{tabular}{lllll} 
Tipo de muestra & \multicolumn{2}{c}{ No clifica } & \multicolumn{2}{c}{ Clínica } \\
Sexo & Varones & Mujeres & Varones & Mujeres \\
& $\mathrm{N}=290$ & $\mathrm{~N}=341$ & $\mathrm{~N}=3.744$ & $\mathrm{~N}=424$ \\
Factor I & .8929 & .8965 & .9004 & .8919 \\
Factor II & .8211 & .8698 & .8482 & .8267 \\
Factor III & .8230 & .8827 & .8496 & .8546 \\
Factor IV & .8163 & .8215 & .8247 & .7891 \\
Factor V & .7016 & .7689 & .7127 & .8152 \\
Factor VI & .7532 & .7077 & .7760 & .7623
\end{tabular}




\section{CONCLUSIONES}

1. De nuestro estudio podemos concluir que la solución de seis factores es la más acertada.

2. Hemos identificado varios factores, algunos de los cuales replican los encontrado por estudios anteriores realizados por diversos autores aplicando el análisis factoriales al mismo inventario, como el Factor I (Evaluación social negativa), Factor II (Fobia a animales en hombres), Factor III (Aprensión al sufrimiento), Factor $V$ en los hombres (Claustrofobia) y Factor VI (Interacción social).

3. Los datos muestran la conveniencia, si no la necesidad, de elaborar inventarios de este tipo independientemente para hombres y mujeres. Esto no sólo por razones metodológicas, sino también porque consideramos más acertado desde un punto de vista clínico, con aplicación tanto en evaluación como en la labor terapéutica y de seguimiento.

Desde hace años hemos defendido la elaboración de inventarios y cuestionarios de personalidad y psicológicos independientes para ambos sexos (Matesanz, 1997). El presente estudio prueba asimismo la elección de tal estrategia.

Más en concreto, como hemos anotado más arriba, en el presente estudio surge un factor que por su consistencia desplaza o sustituye al factor masculino CLAUSTROFOBIA. Es, pues, una dimensión típica de los temores femeninos que señala la importancia de recoger en la labor de evaluación con la mujer esa SENSIBILIDAD ANTE LA VIOLENCIA, esa tendencia desarrollada fundamentalmente en la mujer y que puede ser relevante en el diagnostico de la violencia de género. Intentamos en la actualidad estudiar este fenómeno con mujeres maltratadas.

Aunque en menor medida, la composición de los factores III, IV y $\mathrm{VI}$, con un ítem diferente en hombres y en mujeres, revela aspectos diferentes de la psicología femenina y masculina, si analizamos el contenido de ciertos comportamientos de un sexo y de otro; por ejemplo, la aprensión al sufrimiento se expresa más en los hombres por "pensar que quizá tenga que operarme", en las mujeres por el temor a «los médicos" (Factor III).

El «tener pensamientos homosexuales" indicaría según nuestro estudio una tendencia obsesiva en los hombres, mientras que dicha 
tendencia se mostraría en las mujeres más por el temor o preocupación a «dejar abierta la puerta de la calle» (Factor IV). ¿Revela esto que la homosexualidad preocupa más al hombre que a la mujer $y$, en consecuencia la rechazará con mayor intensidad?

Asimismo, el pudor masculino al rechazar los "reconocimientos corporales" no se ve reflejado al mismo nivel en las mujeres, a quienes afecta más el "estar en un lugar extraño" (Factor VI).

4. Puede ser interesante resaltar la inclusión del ítem "temor a enfadarme» en el Factor $V$ de las mujeres (SENSIBILIDAD ANTE LA VIOLENCIA); inclusión que, dado el significado general de este factor, podría explicarse por el temor o la creencia de la mujer a que su propio enfado pueda provocar la violencia física ajena; según esta hipótesis, las mujeres posibles objeto del maltrato o víctimas de violencia de género tenderian a evitar la denuncia del agresor y, como estrategia de defensa, prefieren la sumisión obediente.

5. La comparación de puntuaciones medias de los items (Tabla 2) confirma la tendencia general de estudios semejantes al nuestro en los que las mujeres obtienen una puntuación más elevada que los hombres en pruebas de ansiedad, tendencia que se observa tanto en las muestras clínicas y como en las no clínicas.

Al comparar las puntuaciones medias de los ítems de cada factor, observamos puntuaciones significativamente más elevadas en la muestra clínica de hombres que en la no clínica en el factor I (Tabla 9); por el contrario en las mujeres (Tabla 10), dicha tendencia se observa fundamentalmente en el Factor IV (TENDENCIA OBSESIVA) en el que la muestra no clínica tiene puntuaciones significativamente superior a la muestra clínica.

6. Hemos de resaltar asimismo la importancia del Factor $V$ hallado en las mujeres, que no aparece en ninguno de los análisis factoriales calculados con hombres. Este hecho cobra mayor relevancia en la actualidad por el significado de la dimensión psicológica que representa, si tenemos en valoramos estos resultados desde una perspectiva de género, que adquiere mayor repercusión en los últimos años las sociedades occidentales. Se puede dirigir la investigación en este sentido para determinar con más precisión el valor predictivo y/o discriminativo de esta dimensión como reveladora de un rasgo femenino que podría ayudar en la prevención de hechos 
desencadenantes en comportamientos de maltrato físico y psíquico o violencia doméstica.

7. Por último, hemos de anotar que la versión definitiva de este cuestionario de temores de seis dimensiones y 48 items precisa estudios de validación con diversas muestras clínicas, condición imprescindible para poder ser aplicada e interpretada en la práctica terapéutica. Mientras tanto, su aplicación -como versión experimental que es- debería limitarse al campo de la investigación. En este sentido seguimos trabajando con varios colectivos que irán aportando sus datos y conclusiones.

Tabla 9. Diferencia de puntuaciones medias de los items en la muestra clínica y no clínica de hombres

FACTOR I: EVALUACIÓN SOCIAL NEGATIVA

$\begin{array}{cl}\begin{array}{l}\text { Muestra } \\ \text { Clínica } \\ \text { Hombres } \\ N=3.744\end{array} & \begin{array}{l}\text { Muestra } \\ \text { no clínica } \\ \text { Hombres } \\ N=290\end{array} \\ & \\ 2,74^{* *} & 2,56 \\ 2,84^{* *} & 2,60 \\ 3,16^{* *} & 2,90 \\ 3,12 & 3,05 \\ 2,88^{* *} & 2,60 \\ 3,19^{* *} & 2,87 \\ 3,52 & 3,59 \\ 3,17^{*} & 3,03\end{array}$

FACTOR II: FOBIA A ANIMALES INOFENSIVOS

$\begin{array}{lll}\text { 20. Los gusanos } & 1,80 & 1,87 \\ \text { 44. Los insectos que andan a rastras } & 2,04 & 2,12 \\ \text { 81. Las arañas inofensivas } & 1,85 & 1,85 \\ \text { 65. Las serpientes no venenosas } & 2,59 & 2,45 \\ \text { 24. Los murciélagos } & 1,72 & 1,72 \\ \text { 28. Los insectos voladores } & 1,78 & 1,86 \\ \text { 55. Los ratones o las ratas } & 2,52 * * & 2,31 \\ \text { 21. Los seres imaginarios } & 1,49 & 1,59\end{array}$

67 Sentirme ignorado por los demás

64. Sentirme criticado por otros

61. Sentirme rechazado por otros

75. Cometer errores

49. Que me critiquen

76. Parecer ridículo

16. Fracasar

77. Perder el control

$3,17^{*} \quad 3,03$ 
FACTOR III: APRENSIONN AL SUFRIMIENTO FÍSICO

\begin{tabular}{|c|c|}
\hline $\begin{array}{l}\text { Muestra } \\
\text { Clinica } \\
\text { Hombres } \\
N=3.744\end{array}$ & $\begin{array}{l}\text { Muestra } \\
\text { no clínics } \\
\text { Hombres } \\
N=290\end{array}$ \\
\hline 1,97 & 1,86 \\
\hline $2,25^{* *}$ & 2,04 \\
\hline 1,49 & 1,59 \\
\hline 1,68 & 1,67 \\
\hline 2,48 & 2,56 \\
\hline $2,95^{*}$ & 2,77 \\
\hline 2,85 & $3,06^{*}$ \\
\hline 2,80 & 2,89 \\
\hline
\end{tabular}

\section{FACTOR IV: TENDENCIA OBSESIVA}

118. Los pensamientos de suicidio

84. Pensar que puedo enfermar mentalmente

113. Pensar que pueden abusar sexualmente de mí

119. Pensar que puedo tener un hijo anormal

96. Tener pensamientos homosexuales

95. Que Dios me castigue

2,20

107. Dejar el gas abierto

3,35

2,31

108. La incapacidad sexual (impotencia)

$3,97 * \quad 3,32$

\section{FACTOR V: CLAUSTOFOBIA}

11. Los automóbiles

31. Los viajes en coche

59. Los lugares cerrados

52. Subir en un ascensor

62. Los viajes en avión

33. La multitud

43. Los viajes en autobús

15. Las sirenas

FACTOR VI: INTERACCIÓN SOCIAL:

123. Tener que tomar decisiones

82. Tener responsabilidades

17. Entrar en una sala donde hay otras personas sentadas

23. Las personas desconocidas

117. Los reconocimientos corporales

06. Hablar en público

90. Que me vean con rayos $X$

39. Que me observen mientras trabajo

$\begin{array}{ll}1,37 & 1,43 \\ 1,29 & 1,32 \\ 1,91 * & 1,79 \\ 1,31 & 1,29 \\ 1,78 & 1,78 \\ 2,17 & 2,29 \\ 1,60 & 1,62 \\ 1,86 & 1,88\end{array}$

$\begin{array}{ll}1,89 * * & 1,73 \\ 1,88 & 1,77 \\ & \\ 1,72 & 1,81 \\ 1,57 & 1,56 \\ 1,57 & 1,55 \\ 2,54 & 2,61 \\ 2,10 & 2,17 \\ 2,13 & 2,02\end{array}$


Tabla 10. Diferencia de puntuaciones medias de los items en la muestra clínlca y no clínlca de mujeres

$\begin{array}{ll}\text { Muestra } & \text { Muestra } \\ \text { Clínica } & \text { no clínica } \\ \text { Mujeres } & \text { Mujeres } \\ \mathrm{N}=424 & \mathrm{~N}=341\end{array}$

FACTOR 1: EVALUACIÓN SOCIAL NEGATIVA

$\begin{array}{lll}\text { 64. Sentirme criticada por otros } & 3,17^{* *} & 2,96 \\ \text { 49. Que me critiquen } & 3,14 & 2,94 \\ \text { 61. Sentirme rechazada por otros } & 3,45 & 3,29 \\ \text { 67. Sentirme ignorada por los demás } & 3,15 & 2,99 \\ \text { 76. Parecer ridiculo } & 3,36^{*} & 3,16 \\ \text { 75. Cometer errores } & 3,32^{*} & 3,16 \\ \text { 16. Fracasar } & 3,52 & 3,71^{*}\end{array}$

FACTOR II: FOBIA A ANIMALES INOFENSIVOS

$\begin{array}{lll}\text { 20. Los gusanos } & 2,56 & 2,61 \\ \text { 44. Los insectos que andan a rastras } & 2,93 & 2,98 \\ \text { 81. Las arañas inofensivas } & 2,55 & 2,70 \\ \text { 65. Las serpientes no venenosas } & 3,23 & 3,24 \\ \text { 24. Los murciélagos } & 2,54 & 2,57 \\ \text { 28. Los insectos voladores } & 2,43 & 2,41 \\ \text { 55. Los ratones o las ratas } & 3,29 & 3,28 \\ \text { 21. Los seres imaginarios } & 1,87 & 1,93\end{array}$

FACTOR III: APRENSIÓN AL SUFRIMIENTO FÍSICO

57. La sangre de los animales 2,41

56. La sangre humana $\quad 2,57$

2,31

29. Ver cómo ponen una inyección a otra persona $2,03 \quad 1,96$

02. Las heridas abiertas $\quad 2,84 \quad 2,79$

53. Presenciar operaciones quirúrgicas $\quad 3,31 \quad 3,23$

73. Los médicos $\quad 1,76 \quad 1,77$

05. Las personas muertas $\quad 3,36 \quad 3,33$

FACTOR IV: TENDENCIA OBSESIVA

118. Los pensamientos de suicidio

84. $2,78 \quad 3,14$ *

84. Pensar que puedo enfermar mentalmente $\quad 3,24 \quad 3,32$

113. Pensar que pueden abusar sexualmente de $\mathrm{m} i 3,55 \quad 3,97^{* *}$

119. Pensar que puedo tener un hijo anormal $3,81 \quad 4,11^{* *}$

102. Dejar abierta la puerta de la calle $2,65 \quad 2,99^{* *}$

95. Que Dios me castigue $\quad 2,20 \quad 2,57^{* *}$

107. Dejar el gas abierto $3,32 \quad 3,72^{* *}$

108. La incapacidad sexual (inapetencia $\quad 3,78^{* *} \quad 3,27$ 


$\begin{array}{ll}\text { Muestra } & \text { Muestra } \\ \text { Clínica } & \text { no clínica } \\ \text { Mujeres } & \text { Mujeres } \\ N=424 & N=341\end{array}$

FACTOR V: HIPERSENSIBILIDAD ANTE LA VIOLENCIA

35. Ver cómo una persona aterroriza a otra 3,57

45. Presenciar una pelea

54. Las personas enfadadas

2,91

36. Las personas de aspecto malvado

3,30

26. Enfadarme

2,80

41. Las armas

3,07

04. Las voces estridentes

2,86

33. La multitud

2,36

FACTOR VI: INTERACCIÓN SOCIAL:

123. Tener que tomar decisiones

82. Tener responsabilidades

17. Entrar en una sala donde hay otras personas sentadas

23. Las personas desconocidas

$1,76 \quad 1,72$

9. Estar en un lugar extraffo

06. Hablar en público

90. Que me vean desnuda

39. Que me observen mientras trabajo

* $p<0.05 ;{ }^{* *} p<0.01$

\section{REFERENCIAS BIBLIOGRÁFICAS}

Akutagawa, D. (1956) A study in construct validity of the psychoanalytic concept of latent anxiety and a test of a projection hypothesis. Tesis doctoral, Universidad de Pittsburgh. Citado por James H. Geer (1965).

Arrindell, W. A.; Pickersgill,M.J.;Merckelbach,H; Ardon,A.M. y Cornet,F.C. (1991) Phobic dimensions: III. Factor analytic approaches to the study of common phobic fears; an updated review findings obtained with adult subjects. Advanc. Behav. Res. Ther., 13, 73-130.

Bernstein, D.A. y Allen, GJ. (1969) Fear survey schedule (II): Normative data an factor analyses based upon a large college sample. Behav. Res. Ther., 1969, 403-7.

Braun, P. R. y Reynolds, D. J. (1969) A factor analysis of a 100-item fear survey inventory. Behav. Res. Ther., 1969, 7, 399-402. 
Fredrikson,M., Annas,P., Fischer,H. Y Wik,G (1996) Gender and age differences in the prevalence of fears and phobias. Behav. Res. Ther., 34,33-39.

Geer, J.H. (1965) The development of a scale to measure fear. Behav. Res. Ther., 1965, 3, 45-53

Lang, P. J. (1963) 122 item fear survey schedule. Comunicación en el Arkansas Rehabilitation Research and Training Center, mayo 1969. Lang, P.J. y Lazovik, A (1963) Experimental desensitization of a fear. J. abnorm. Soc. Psychol., 66, 519-525.

Lawlis, G.F. (1971) Response styles of a patient population on the fear survey schedule. Behav. Res. Ther., 1971, 9, 95-102

Matesanz, A. (1997) Evaluación estructurada de la personalidad. Madrid: Pirámide.

Rubin, B.M., Katkin,E.S., Weiss,B.W. y Efran, J.S. (1968) Factor analysis of a Fear Survey Schedule. Behav. Res. Ther., 6, 65-75.

Rubin, S. E., Tasto, D.L. y Namenek, T. (1969) Factor analysis of the 122 item fear survey schedule. Behav. Res. Ther., 1979, 7, 1969, $381-6$

Sabucedo, J.M., Ibañez,E. y Belloch. A. (1982) Estudio factorial de la escala de temores de Wolpe. Anál. Modif. Cond., 8, 29-45

Stratton, T.T. y Moore, C.L. (1977) Application of the robust factor concept to the fear survey schedule. J. Behav. Ther. Exp. Psychiat., 1977, 8,229-35

Wolpe. J. y Lang, P.J. (1964) A fear survey schedule for use in behaviour therapy. Behav. Res. Ther., 1964, 2, 27-30. 


\section{APÉNDICE}

Las frases siguientes se refieren a objetos y experiencias que pueden causarle temor 0 desagrado. A la derecha se presentan cinco respuestas (de unada" a "muchísimo»), según el grado de temor o desagrado que ocasione cada situación. Indique con una " $X$ " la respuesta que Ud. cree corresponde en su caso en la actualidad. Procure, por favor, contestar todas las frases.

ME CAUSA(N) TEMOR O DESAGRADO

1. Las heridas abiertas

Nada

Bas-

Muchi-

1. El ruido de la aspiradora

2. Las heridas abiertas

3. Estar solo/a

4. Las voces estridentes

5. Las personas muertas

6. Hablar en público

7. Cruzar las calles solo/a

8. Ver personas que parecen enfermos mentales

9. Estar en un lugar extrano

10. Caerme

11. Los automóviles

12. Que me molesten

13. Los dentistas

14. Los truenos

15. Las sirenas

16. Fracasar

17. Entrar en una sala donde hay otras personas sentadas

18. Los lugares altos en el campo .

19. Mirar hacia abajo desde edificios altos

20. Los gusanos

21. Los seres imaginarios

22. Que me pongan una inyección

23. Las personas desconocidas

24. Los murciélagos

25. Los viajes en tren

26. Enfadarme

27. Las personas con autoridad

28. Los insectos voladores

29. Ver cómo ponen una inyección a otra persona

30. Los ruidos inesperados

31. Los viajes en coche

32. El tiempo nebuloso

33. La multitud

34. Los gatos

35. Ver cómo una persona atemoriza a otra

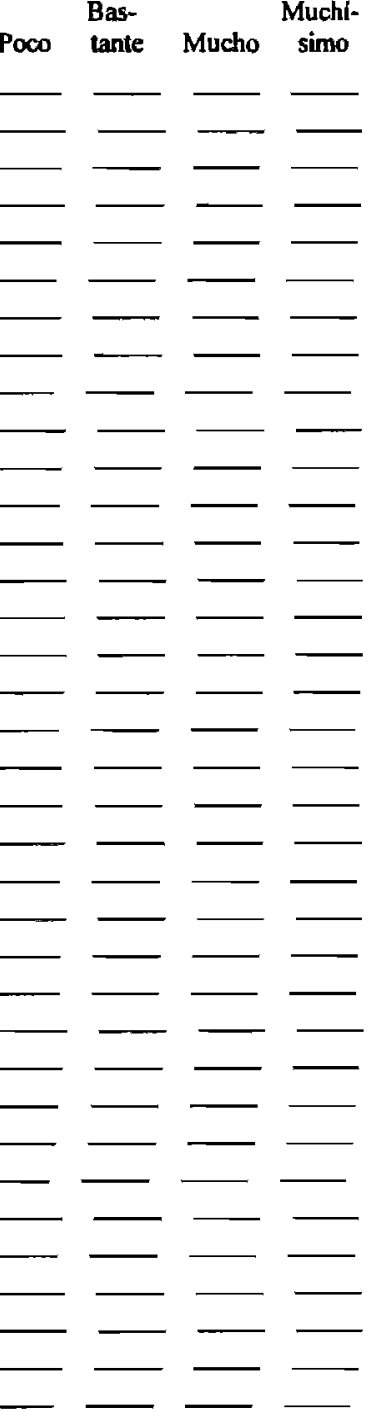


36. Las personas de aspecto malvado

37. Los pájaros

38. Ver aguas profundas

39. Que me observen mientras trabajo

40. Los animales muertos

41. Las armas

42. La suciedad

43. Los viajes en autobús

44. Los insectos que andan a rastras

45. Presenciar una pelea

46. Las personas feas

47. El fuego

48. Las personas enfermas

49. Que me critiquen

50. Las formas extrafias

51. Que otros me toquen

52. Subir en un ascensor

53. Presenciar operaciones quirúrgicas

54. Las personas enfadadas

55. Los ratones o las ratas...

56. La sangre humana

57. La sangre de los animales

58. Despedirme de los amigos

59. Los lugares cerrados

60. Pensar que quizá tenga que operarme

61. Sentirme rechazado/a por otros

62. Los viajes en avión...

63. Los olores a medicina

64. Sentirme criticado/a por otros

65. Las serpientes no venenosas

66. Los cementerios

67. Sentirme ignorado/a por los demás

68. La oscuridad

69. No sentir a veces latir el corazón

70. Los hombres desnudos

71. Las mujeres desnudas

72. Los relámpagos

73. Los médicos

74. Las personas mutiladas o deformes

75. Cometer errores

76. Parecer ridículo/a

77. Perder el control

78. Desmayarme

79. Sentir náuseas

80. Sentirme diferente a los demás

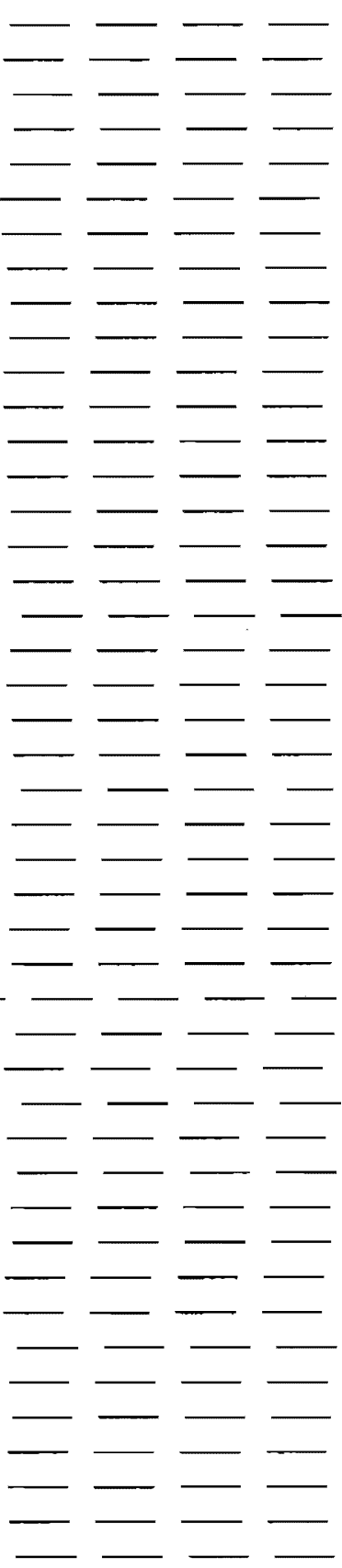


81. Las arañas inofensivas

82. Tener responsabilidades

83. Ver cuchillos $u$ objetos punzantes

84. Pensar que puedo enfermar mentalmente

85. Hacer exámenes escritos

86. Estar con personas del sexo opuesto

87. Los espacios grandes y abiertos

88. Los perros

89. Los microbios

90. Que me vean desnudo/a

91. Las drogas

92. Despedir un olor desagradable

93. Ser feo/a

94. Estar excitado/a sexualmente

95. Que Dios me castigue

96. Tener pensamientos homosexuales

97. Que otros me dominen

98. La pérdida de seres queridos

99. Llevar ropa impropia de la situación

100. Los sacerdotes

101. Herir los sentimientos de otra persona

102. Dejar abierta la puerta de la calle

103. Los besos

104. Que me miren por rayos X.

105. Reír o llorar de forma incontrolada

106. Los enterradores

107. Dejar el gas abierto

108. La incapacidad sexual (impotencia o frigidez)

109. Las puertas o las ventanas abiertas

110. El embarazo

111. La policía

112. Los peces, el pescado

113. Pensar que pueden abusar sexualmente de mí

114. Los edificios donde ha muerto alguien

115. La masturbación

116. Salir de casa

117. Los reconocimientos corporales

118. Los pensamientos de suicidio

119. Pensar que puedo tener un hijo anormal

120. Entrar solo/a en un teatro con las luces apagadas

121. El matrimonio

122. Los insecticidas

123. Tener que tomar decisiones

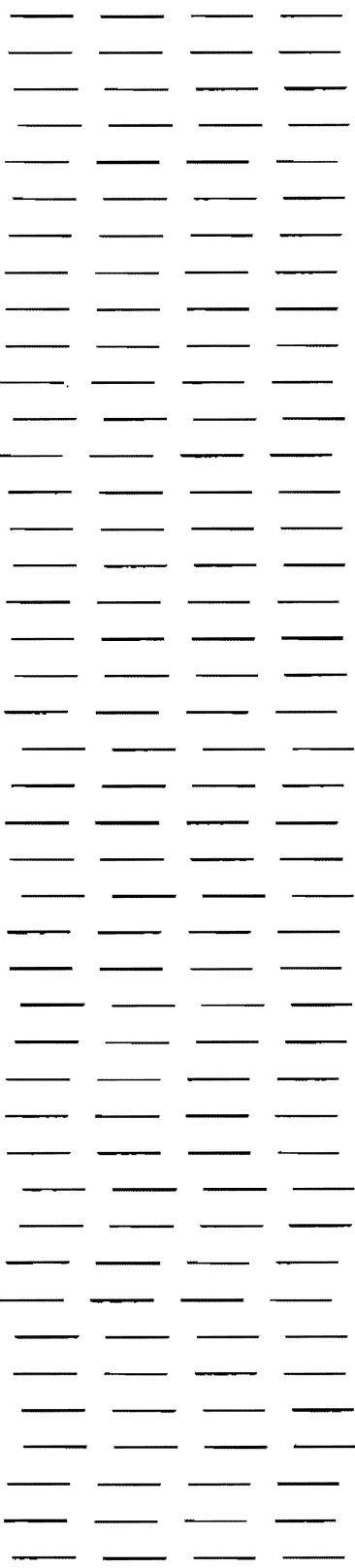




\section{Fe de erratas}

En el presente artículo el nombre propio del autor es «Agripino» en lugar del que aparece en la página 521 y en los encabezamientos de las sucesivas páginas pares. 